Recebido em 01/2020. Aceito para publicação em 03/2020.

\title{
OTIMIZAÇÃO DE PROCESSO BIOTECNOLÓGICO UTILIZANDO RESÍDUO DA INDÚSTRIA CERVEJEIRA NA PRODUÇÃO DA ENZIMA TANASE
}

\section{OPTIMIZATION OF BIOTECHNOLOGICAL PROCESS USING RESIDUES OF THE BREWING INDUSTRY IN TANNASE ENZYME PRODUCTION}

\author{
Ester Helena Alves ${ }^{1}$ \\ Suelene FS Bispo dos Santos ${ }^{2}$ \\ Priscila Hoffmann Carvalho ${ }^{3}$ \\ Vania Battestin Wiendl ${ }^{4}$
}

Resumo: Os resíduos agroindustriais são produzidos em grandes quantidades a partir do beneficiamento e industrialização de alimentos. O descarte desses resíduos no meio ambiente pode resultar em uma série de transtornos para o ecossistema, devido à sua rica composição em matéria orgânica. Diante desse cenário, o reaproveitamento dos resíduos industriais é uma alternativa viável para a diminuição dos impactos ambientais causados pelo descarte inadequado e atendimento das exigências legais referentes à destinação final dos resíduos produzidos. Neste contexto, destaca-se a indústria cervejeira, cuja produção inclui etapas de processamento e fermentação de matéria-prima vegetal, gerando resíduos caracterizados por composições que apresentam significativo potencial para aplicação em tecnologias de bioprocessos através de rotas biotecnológicas sustentáveis. Dentre vários metabólitos de interesse industrial, a enzima tanase vem se destacando no cenário nacional devido a sua capacidade de produzir antioxidantes utilizados na indústria química, farmacêutica e alimentícia. O trabalho objetiva a otimização do meio de fermentação sólida para produção desta enzima utilizando resíduos da indústria cervejeira. Para isso, os resíduos foram padronizados e submetidos ao processo fermentativo, onde foram estudadas diversas variáveis da rota de produção do composto. Assim, como principal resultado, destaca-se o aumento da atividade enzimática, que passou de 0,04 U/mL para $0,19 \mathrm{U} / \mathrm{mL}$ após os ajustes do agente extrator, umidade do meio fermentativo, tempo de incubação e $\mathrm{pH}$, concentração do agente indutor e temperatura e $\mathrm{pH}$ do meio reacional. Portanto, foram estabelecidos os melhores padrões para otimização do processo, reafirmando o resíduo da indústria cervejeira como um ótimo substrato para produção de biomoléculas.

Palavras-chave: Bioprocessos; fermentação sólida; otimização de bioprocessos; tanase.

Abstract: Agroindustrial residues are produced in large quantities from food processing and beneficiation. The disposal of these residues into the environment can result in a number of disruptions in the ecosystem due to their composition rich in organic matter. In this scenario, the reuse of industrial residues is a viable alternative for reducing the environmental impacts caused by improper disposal and compliance with legal requirements regarding the final disposal of the residues produced. In this context, the brewing industry stands out, whose production includes processing and fermentation stages of vegetable raw material, generating residues characterized by compositions that have significant potential for application in bioprocess technologies using sustainable biotechnological routes. Among several metabolites of industrial interest, the enzyme tannase has been emphasized in the national scenario due to its capacity to produce antioxidants used in the chemical, pharmaceutical and food industry. The work aims to optimize the solid fermentation medium for the production of this enzyme using residues from the brewing industry. For that,

\footnotetext{
${ }^{1}$ Graduanda em Licenciatura em Química, Instituto Federal de Educação, Ciência e Tecnologia de São Paulo Campus São José dos Campos, Brasil. E-mail: esterhelena15@gmail.com

2 Técnica em Química Instituto Federal de Educação, Ciência e Tecnologia de São Paulo - Campus São José dos Campos, Brasil. E-mail: suelene@ufrj.br.

3 Doutora em Ciência de Alimentos pela Universidade Estadual de Campinas - Unicamp, Brasil. E-mail: priscila.fea@gmail.com.

4 Doutora em Ciência de Alimentos. Docente na Instituto Federal de Educação, Ciência e Tecnologia de São Paulo - Campus São José dos Campos, Brasil. E-mail: vbattestin@ifsp.edu.br.
} 
the residues were standardized and submitted to the fermentation process, where several variables of the compound production route were studied. Thus, as the main result, we highlight the increase in enzymatic activity, which changed from $0.04 \mathrm{U} / \mathrm{mL}$ to $0.19 \mathrm{U} / \mathrm{mL}$ after adjusting the extracting agent, moisture in the fermentation medium, incubation time and $\mathrm{pH}$, concentration of the inducing agent and temperature and $\mathrm{pH}$ of the reaction medium. Therefore, the best standards for process optimization were established, reaffirming the residue from the brewing industry as a great substrate for biomolecule production.

Keywords: Bioprocesses; solid fermentation; bioprocess optimization; tannase.

\section{INTRODUÇÂO}

A indústria de alimentos produz diversos resíduos com grande potencial de (re)utilização e alto valor agregado quando aplicado para o desenvolvimento biotecnológico. Além de fonte de matéria orgânica, os resíduos agroindustriais são amplamente empregados como fonte de proteínas, enzimas e óleos essenciais. Tendo em vista a crescente dinâmica das políticas ambientais, o desenvolvimento de processos biotecnológicos a partir de resíduos antes descartados, dentre os quais estão os processos enzimáticos, é de grande relevância no cenário mundial. Deste modo, a utilização de resíduos provenientes da indústria cervejeira da Região do Vale do Paraíba e Região Sul do país busca agregar valor e potencializar a produção de enzimas, visando não somente a produção em escala laboratorial (COELHO et al., 2001; PELIZER; PONTIERI; MORAES, 2007).

Sabe-se ainda que devido as características de reprodução e crescimento dos fungos, estes se adequam a diversos substratos, assim, a utilização de microorganismos para a produção de enzimas por intermédio da fermentação sólida surge como alternativa a utilização dos resíduos da indústria de alimentos que antes eram descartados ou pouco aproveitados. A fermentação em estado sólido (FES) se refere ao processo de crescimento de micro-organismos sobre substratos sólidos sem a presença de água livre circulante, de modo que a água presente no sistema se encontra complexada com a matriz sólida (BATTESTIN; MATSUDA; MACEDO, 2004), esta se mostra bastante vantajosa para a produção de enzimas, pois, além de ser um meio de produção simples, utiliza subprodutos agroindustriais ricos em taninos e acrescidos de ácido tânico (LAGEMAAT; PYLE, 2001; SILVA et al., 2018). Dessa forma, o resíduo da produção artesanal e industrial de cerveja, mercado bastante difundido na região, configura-se como um potencial substrato para a produção de tanase, a partir do fungo Aspergillus niger.

As enzimas são biocatalisadores, responsáveis por milhares de reações bioquímicas envolvidas nos mais diversos processos biológicos, tanto nos seres vivos quanto industrialmente (KIELING, 2002). Tanino acil hidrolase, conhecida como tanase (EC 3.1.1.20), é uma enzima extracelular, induzível, produzida por fungos, bactérias e leveduras, na presença de ácido tânico. Trata-se de uma enzima que hidrolisa ésteres e ligações laterais de taninos hidrolisáveis obtendo como produto a glicose e o ácido gálico. Aplicada na indústria de alimentos, sucos, cervejaria, cosméticos, farmacêutica e indústria química; é usada na produção de ácido gálico, chás instantâneos, na 
estabilização da cor do vinho, refrigerantes a base de café, processo de tratamento de couro, detanificação de alimentos e para tratamento de efluentes na indústria de couros. Entretanto, apesar de muitas aplicações potenciais da enzima tanase, poucas são efetivamente exploradas em virtude, principalmente, do alto custo de produção da mesma (AGUILAR, C. et al., 1999; BANERJEE; MONDAL; PATI, 2001; BATTESTIN; MATSUDA; MACEDO, 2004; VALERA, 2014).

Visto isso, o presente trabalho busca utilizar os resíduos da indústria cervejeira na produção da enzima tanase por meio de fermentação em estado sólido, testando as melhores condições para a produção do composto, visando a otimização do processo biotecnológico.

\section{FUNDAMENTAÇÃO TEÓRICA}

\subsection{Resíduo da produção de cerveja}

Os setores agroindustriais e de alimentos produzem grandes quantidades de resíduos, que podem apresentar elevados problemas de disposição final e potencial poluente, além de representarem, muitas vezes, perdas de biomassa e de nutrientes de alto valor. Assim, conceitos de minimização, recuperação, aproveitamento de subprodutos e bioconversão de resíduos são cada vez mais difundidos e necessários para as cadeias agroindustriais (ROCHA, 2010; BORGES; SOUZA NETO, 2009).

A indústria brasileira de cerveja gera grandes quantidades de resíduos sólidos (bagaço de cevada), resultantes dos processos efetuados. Estima-se que a quantidade de resíduo de cevada produzida anualmente no Brasil seja de aproximadamente dois milhões de toneladas, quantidade esta que representa $85 \%$ dos subprodutos do processo. Sua composição, com elevado teor de proteínas e carboidratos, envolve principalmente materiais nitrogenados, fibra, lipídeos e lignina. A cada 100 litros de cerveja produzidos são gerados cerca de $20 \mathrm{~kg}$ de bagaço, utilizados somente como ração animal (MATHIAS; MELO; SERVULO, 2014).

Nesse aspecto, visando à obtenção de produtos de maior valor agregado e a destinação dos resíduos gerados para fins mais nobres, os bioprocessos industriais apresentam-se como potenciais meios para destinação destes rejeitos (PANDEY et al., 2001), além de suas possíveis aplicações em alimentação animal e humana. Além disso, na região de São José dos Campos estão localizadas várias cervejarias de pequeno, médio e grande porte. Destacando-se as cervejarias Ambev (Brahma, Skol, Antartica, Original, entre outras) e Heineken (Amstel, Proibida, Schin, e outras) localizadas no município de Jacareí.

\subsection{Utilização de fungos em bioprocessos}

$\mathrm{Na}$ busca de soluções alternativas para o problema do descarte dos resíduos, muitas indústrias têm optado pelo uso de micro-organismos como agentes redutores de 
matéria orgânica para eliminação ou redução de compostos tóxicos. Os fungos, em função de suas características de reprodução e crescimento, adaptam-se a diversos substratos, entre os quais efluentes de indústrias processadoras de alimentos, resíduos agrícolas e agroindustriais e resíduos derivados de petróleo (KRONBAUER et al., 2007).

Diversos resíduos estão sendo aproveitados como substratos na produção de enzimas pelos micro-organismos. Resíduos como farelo de trigo, bagaço de cana, resíduos do processamento de suco de laranja, têm sido utilizados para produção de tanase utilizando diferentes micro-organismos (BATTESTIN, 2007).

\subsection{Otimização dos Processos}

A maioria dos estudos na área de bioprocessos envolve o entendimento do mecanismo de produção, para selecionar o melhor biocatalisador (micro-organismo ou enzima), as melhores condições ambientais que propiciam um melhor rendimento, a procura de recursos mais econômicos, mas que ainda produzam um rendimento satisfatório. $O$ estudo de um processo fermentativo envolve também o desenvolvimento de uma estratégia de otimização, obtendo-se assim um melhor rendimento do produto. A otimização pode ser feita ajustando várias etapas do processo, sendo algumas delas mais facilmente modificadas do que outras. São geralmente alterados alguns dos parâmetros relacionados com os quatro pilares da fermentação: no micro-organismo, no substrato, nas condições operacionais, e nos processos de recuperação do produto (PERLINGEIRO, 2005; TEIXEIRA; VAZ; BATTESTIN, 2017).

\subsection{Otimização dos Processos}

O grande interesse industrial pela enzima tanase está relacionado com seu potencial de aplicação em diversas indústrias e sua eficiência vem sendo estudada atualmente nos processos de produção de antioxidantes em chás comerciais (BATTESTIN, 2007), na erva mate, suco de laranja (FERREIRA, 2011) e ração animal (SCHONS; RIES; MACEDO, 2012). As tanases ainda podem ser utilizadas no tratamento de efluentes da indústria de couro, na produção de vinhos, na produção de medicamentos e fármacos. Atualmente o mercado nacional é suprido com essa enzima apenas via importação.

A partir disso, espera-se que esse trabalho contribua para a tecnologia nacional de produção de enzimas, principalmente na produção da enzima tanase, que é o estado da arte desse projeto. Além de colaborar com diversas indústrias alimentícias, químicas e farmacêuticas, tanto no que diz respeito a utilização de um subproduto gerado pela agroindústria, quanto no desenvolvimento de rotas biotecnológicas sustentáveis e na produção de uma biomolécula com ampla possibilidade de emprego e interesse industrial ainda não produzida em grande escala no âmbito nacional. 


\section{MATERIAIS E MÉTODOS}

\subsection{Materiais e equipamentos utilizados}

Resíduos: Os resíduos da indústria cervejeira e da produção artesanal da bebida foram doados por empresas e produtores da região de São José dos Campos e do Sul do país.

Reagentes químicos e meios de cultura: ácido tânico, SDS-trietanolamina, sais minerais e tampões, PDA (Ágar de Batata Dextrosado), resíduos da indústria cervejeira e de aguardente de Cambuci, proteína BSA (albumina de soro bovino).

Equipamentos: Espectrofotômetro (Metash-Tecnal); Banho termostático (Tecnal); Centrífuga (Kasvi k14-4000); Estufa de Cultura (Tecnal TE-392-1); Incubador Shaker (K-330-Pro); Balança analítica (Mettler Toledo Me 104), pHmetro (Metler Toledo).

\subsection{Métodos}

\subsubsection{Padronização dos resíduos}

As amostras dos resíduos foram padronizadas em relação a secagem dos resíduos em estufa, determinação do $\mathrm{pH}$ e determinação de granulometria, visando a homogeneização dos resíduos para o processo fermentativo.

As amostras dos resíduos foram desidratadas em estufa a aproximadamente $75^{\circ} \mathrm{C}$. Para a determinação do $\mathrm{pH}$ foram adicionados $40 \mathrm{~mL}$ de água destilada a $4,0 \mathrm{~g}$ de amostra, e a mistura foi vigorosamente agitada - por 15 minutos, no Shaker, a 200 rpm - até que as partículas se mostrassem uniformemente suspensas. Após 10 minutos, o $\mathrm{pH}$ do sobrenadante foi determinado em pHmetro (INSTITUTO ADOLFO LUTZ, 2008). Além disso, foram determinados os tamanhos médios das partículas dos resíduos estudados.

\subsubsection{Micro-organismo, conservação e preparo do inóculo}

A linhagem fúngica que foi utilizada no presente estudo foi isolada do solo da árvore conhecida popularmente com Ingá. Posteriormente esta linhagem foi identificada como sendo Aspergillus niger. A linhagem fúngica foi conservada em tubos de ensaio com meio de ágar batata dextrose (PDA), inclinados e em temperatura de $10^{\circ} \mathrm{C}$. A linhagem foi repicada em meio PDA inclinado, com suplemento de ácido tânico $0,2 \%$ (p.v-1), pH final do meio igual a 5,2 e incubadas em estufa à $32^{\circ} \mathrm{C}$ por 120 horas para pré-indução da tanase.

\subsubsection{Meio de fermentação sólida para produção da tanase}


O meio de fermentação foi preparado adicionando $20 \mathrm{~g}$ da mistura do resíduo na proporção 1:1, acrescido de solução de sais e ácido tânico, ajustável à concentração de $10 \%$ de ácido tânico (agente indutor). O meio foi esterilizado e em seguida os frascos foram inoculados com $2 \mathrm{~mL}$ de solução de esporos e incubados a $32^{\circ} \mathrm{C}$ em estufa bacteriológica por 120 horas. Após a fermentação, foram adicionados $70 \mathrm{~mL}$ de solução tampão acetato $0,2 \mathrm{M}$ - pH 5,0 (agente extrator) e agitados a $200 \mathrm{rpm}$ por 1 hora. $\mathrm{A}$ solução foi filtrada em algodão e levada a centrífuga por 15 minutos a $4.000 \mathrm{rpm}$. No sobrenadante foi medida a atividade enzimática de acordo com metodologia proposta por Lekha e Lonsane (1994). Para isso, a solução substrato foi preparada pela adição de ácido tânico $0,2 \%$ (p.v-1) em tampão acetato $0,2 \mathrm{M}(\mathrm{pH} 5,5)$. A reação enzimática foi realizada adicionando $0,3 \mathrm{~mL}$ da solução substrato com $0,5 \mathrm{~mL}$ de extrato enzimático bruto deixado em banho maria à $60^{\circ} \mathrm{C}$ por 10 minutos. Após a incubação, a reação foi paralisada com $3 \mathrm{~mL}$ de solução BSA preparada na concentração de $1 \mathrm{mg} \cdot \mathrm{mL}-1$ de BSA e de cloreto de sódio 0,17 M em tampão acetato 0,2 M ( $\mathrm{pH} 5)$, e em seguida, centrifugada a 4.000 rpm por 15 minutos. Ao precipitado foi adicionado $3 \mathrm{~mL}$ de solução SDS-trietanolamina acrescido de $1 \mathrm{~mL}$ de solução de FeCl3. A absorbância foi medida após 15 minutos a $530 \mathrm{~nm}$ de acordo com metodologia sugerida por Mondal, Banerjee e Jana (2001). A curva padrão foi elaborada utilizando quantidades de ácido tânico comercial variando entre 0,02 e $0,14 \mathrm{mg}$.

Foram testadas variáveis do processo de produção da enzima tanase, tais como: resíduo da produção de cerveja artesanal e industrial, influência do agente extrator e da umidade do meio de FES, influência do tempo de incubação, do pH do meio, do agente indutor, e da temperatura e pH da reação enzimática.

\section{RESULTADOS E DISCUSSÃO}

\subsection{Meio de fermentação sólida para produção da tanase}

As amostras de resíduos da indústria de cerveja foram desidratadas em estufa até a obtenção de partículas secas e não aglomeradas (Figura 1), que apresentaram um tamanho médio de aproximadamente $0,66 \mathrm{~cm} \pm 0,14$.

Figura 1 - Resíduo da indústria cervejeira.

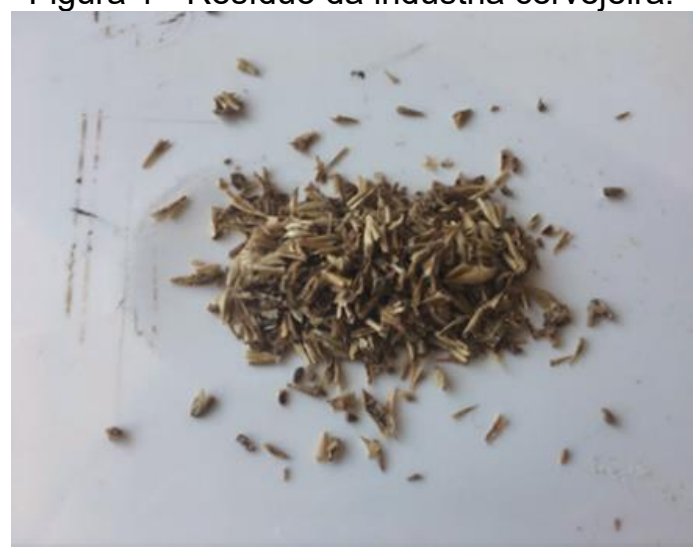

Fonte: Os autores. 
$\mathrm{O}$ pH da amostra foi medido a cada 1 (uma) hora, num período total de 3 (três) horas e manteve-se estável no decorrer das medidas, numa média de 5,24 $\pm 0,02$. 0 caráter ácido observado é proveniente da composição deste resíduo, assim como afirmam os autores Cabral Filho (1999) e Rech e Zorzan (2017), e estão em acordo com o resultado encontrado na literatura, que relatou $\mathrm{pH}=5,96$ para o bagaço de malte úmido (RECH; ZORZAN, 2017):

\subsection{Análise da produção da enzima utilizando resíduo da produção cervejeira}

A Figura 2 apresenta os dados de produção da enzima tanase no resíduo da indústria cervejeira.

Figura 2 - Medida da atividade enzimática utilizando resíduo da produção cervejeira.

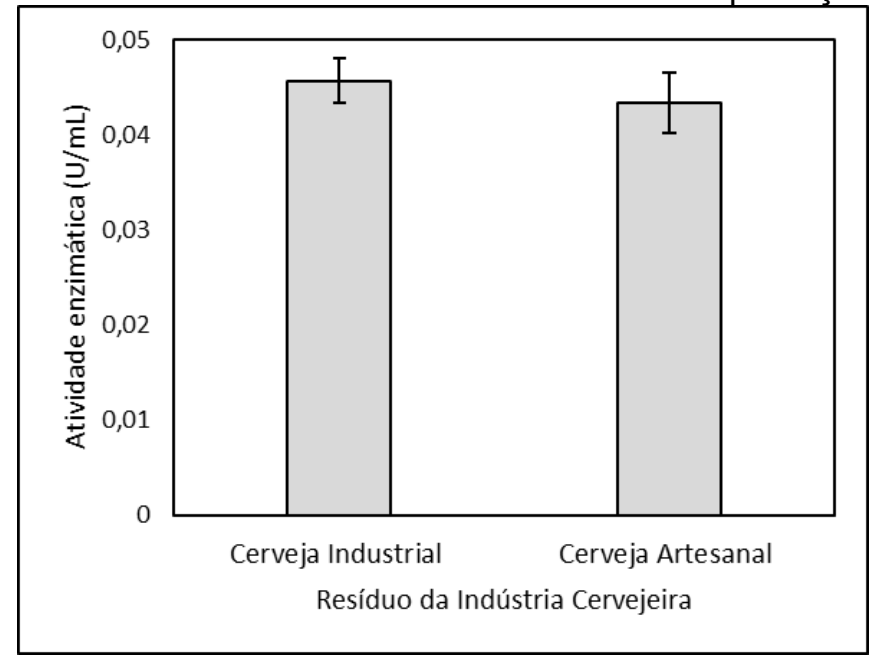

Fonte: Os autores.

A partir disso, constatou-se que a produção da enzima tanase nos resíduos cervejeiros foi de $0,046 \mathrm{U} / \mathrm{mL} \pm 0,002$ para o resíduo da cerveja industrial e de $0,043 \mathrm{U} / \mathrm{mL}$ $\pm 0,003$ para o resíduo da cerveja artesanal. Dessa forma, foi dada a preferência para os estudos com o resíduo proveniente da produção industrial.

\subsection{Influência do agente extrator na produção da enzima}

Foi verificado a influência do agente extrator $\mathrm{NaCl}$ 1,5\% e tampão acetato ( $\mathrm{pH}$ 5,0 - 0,2M) na extração da enzima após a fermentação (Figura 3). 
Figura 3 - Influência do agente extrator na produção da enzima.

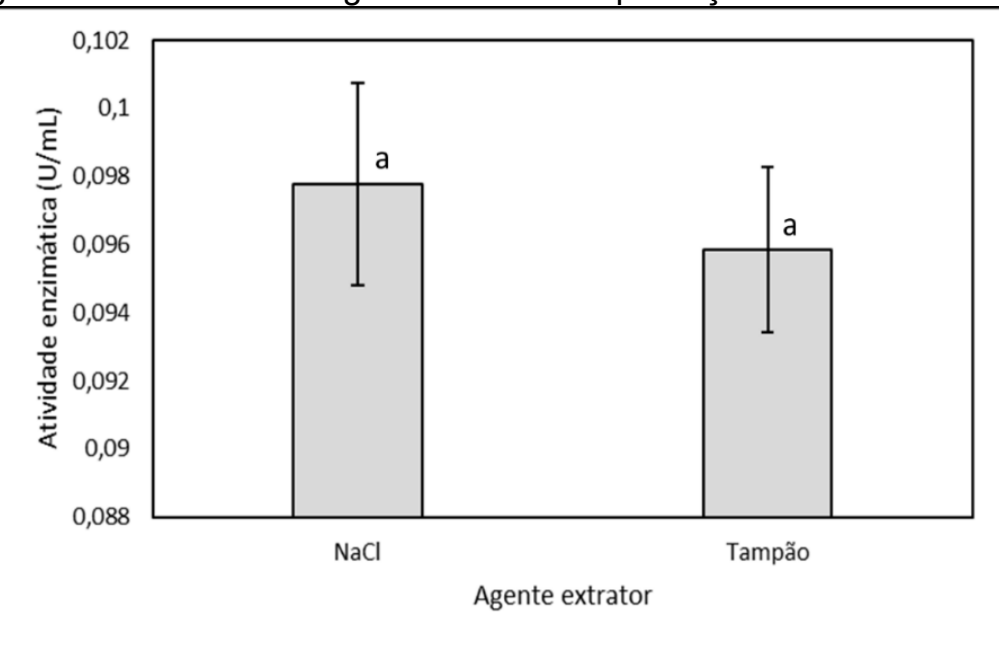

Nota: Colunas com letras iguais não apresentam diferenças significativas para o teste de Tukey $(p>0,05)$. Fonte: Os autores.

A extração da enzima foi maior quando se utilizou $\mathrm{NaCl}(1,5 \%)$, obtendo-se valores de atividade de tanase em torno de 0,098 U/mL. Ao utilizar o tampão acetato $(\mathrm{pH} \mathrm{5,0} \mathrm{-}$ 0,2M), o valor de atividade foi de 0,096 U/mL. Dessa forma, os testes seguintes foram conduzidos com o tampão acetato ( $\mathrm{pH} 5,0-0,2 \mathrm{M})$, posto que não houve diferença significativa na atividade de tanase, segundo o teste de Tukey $(p>0,05)$, e estes resultados estão de acordo com a metodologia relatada na maioria dos estudos que obtiveram bons resultados (BATTESTIN, 2007; EL-FOULY et al., 2010; SCHONS; RIES; MACEDO, 2012; SRIVASTAVA; KAR, 2009).

\subsection{Influência da umidade na produção da enzima}

Foram testadas três diferentes proporções (resíduo: solução de sais acrescido de ácido tânico) no meio de fermentação em estado sólido: (1:0,5), (1:1) e (1:2). Os resultados obtidos estão descritos na Figura 4. 
Figura 4 - Influência da umidade na atividade de tanase.

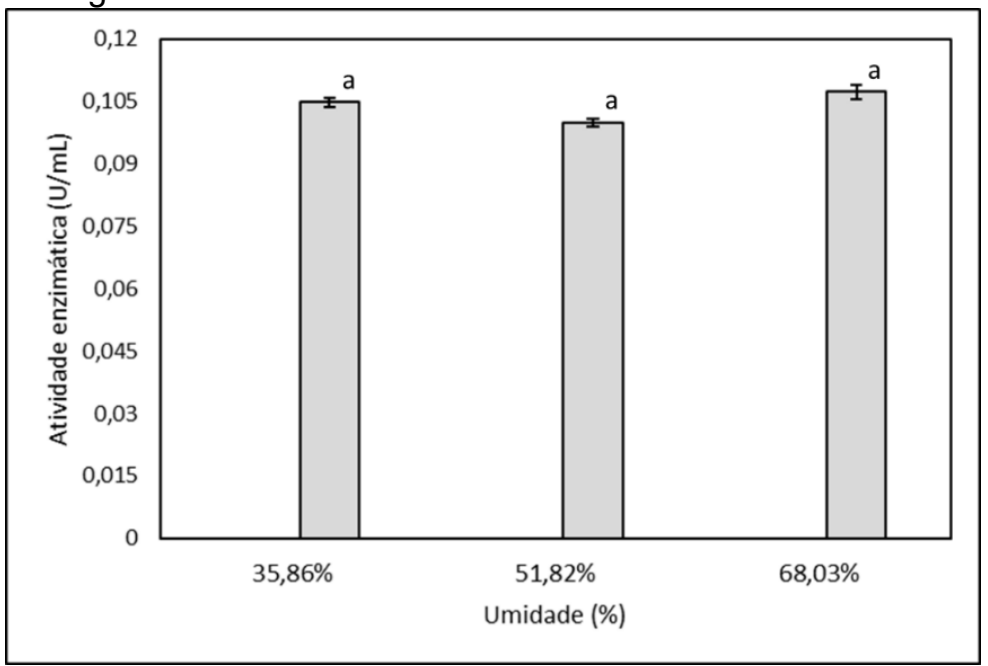

Nota: Colunas com letras iguais não apresentam diferenças significativas para o teste de Tukey $(p>0,05)$. Fonte: Os autores.

A partir disso, comprovou-se que a atividade de tanase foi de $0,104 \mathrm{U} / \mathrm{mL} \pm 0,001$ no meio de fermentação sólida com umidade de 35,86\% (proporção 1:0,5), assim como a enzima demonstrou atividade de $0,099 \mathrm{U} / \mathrm{mL} \pm 0,000$ no meio de FES com umidade de $51,82 \%$ e $0,107 \mathrm{U} / \mathrm{mL} \pm 0,001$ para a umidade de $68,03 \%$ (respectivamente, nas proporções 1:1 e 1:2). Entretanto, não houve diferença significativa entre os três ensaios descritos, de acordo com o teste de Tukey, além de que, a atividade enzimática permaneceu linear. Logo, os testes seguintes mantiveram a proporção padrão 1:1 (BATTESTIN, 2007; EL-FOULY et al., 2010; SCHONS; RIES; MACEDO, 2012), com umidade de $51,82 \%$.

\subsection{Influência do tempo de incubação e do pH na produção da enzima}

Foram analisados também a influência do tempo de incubação na atividade enzimática, assim como a variação do pH no meio (Figura 5). 
Figura 5 - Influência do tempo de incubação e do pH na produção da enzima.

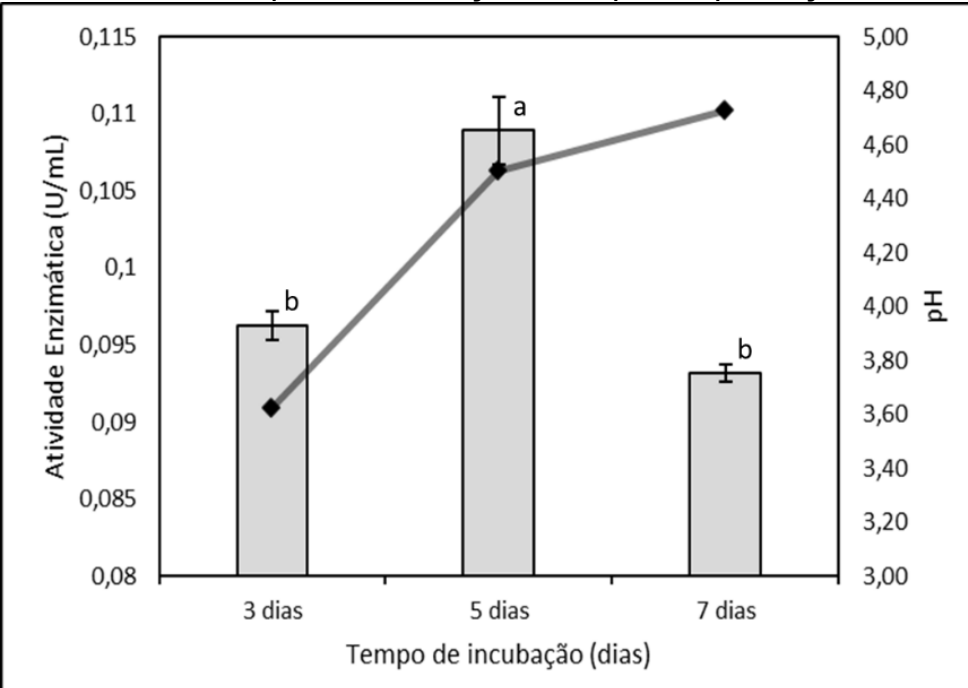

Nota: Colunas com letras distintas são significativamente diferentes para o teste de Tukey $(p<0,05)$.

Fonte: Os autores.

O período ideal de incubação foi de 5 dias, resultados estes semelhantes aos obtidos por El-Fouly et al. (2010) e Teixeira, Vaz e Battestin (2017). Contudo, Lal et al. (2012) relatou a máxima atividade enzimática em 7 dias. Além disso, foi possível constatar que o pH ótimo para a máxima atividade de tanase foi de 4,50 (5 dias). Estes dados são semelhantes aos obtidos por Lal et al. (2012) e El-Fouly et al. (2010), entretanto, Marco et al. (2009) e Srivastava e Kar (2009) relataram pH ótimo para a atividade de tanase em 6,0. A queda na atividade enzimática - com 7 dias - pode ser justificada pelo aumento do $\mathrm{pH}$ à medida que se aumenta o período de incubação, apesar de manter-se com $\mathrm{pH}$ ácido. Provavelmente, a variação do $\mathrm{pH}$ ao longo dos períodos de incubação analisados ocorreu devido aos produtos formados e consumidos no meio durante o processo.

\subsection{Influência do agente indutor no meio de fermentação sólida}

Foram conduzidos ensaios de produção da enzima sem indutor no meio e utilizando as variações de 5\%,10\% e 15\% de indutor (Figura 6). 
Figura 6 - Influência do agente indutor (ácido tânico) no meio de fermentação sólida.

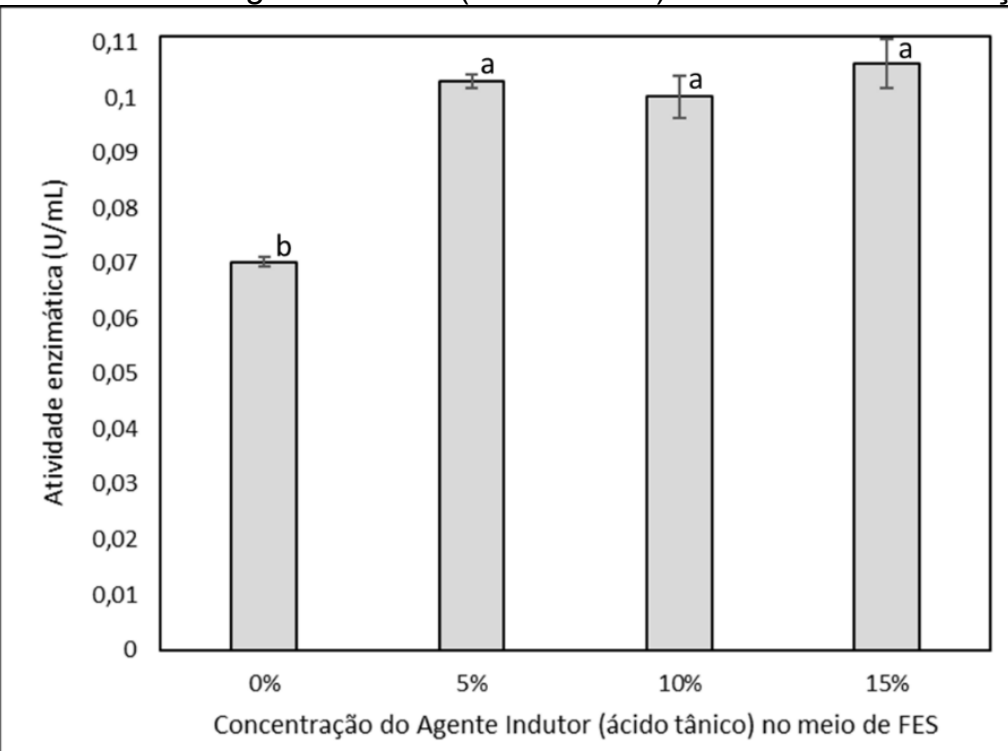

Nota: Colunas com letras distintas são significativamente diferentes para o teste de Tukey $(p<0,05)$. Fonte: Os autores.

Foi possível constatar que a adição de indutor proporciona uma diferença significativa na produção da enzima tanase, posto que a atividade enzimática foi de 0,07 $\mathrm{U} / \mathrm{mL} \pm 0,001$ sem o referido aditivo e apresentou valores de $0,10 \mathrm{U} / \mathrm{mL} \pm 0,001,0,10$ $\mathrm{U} / \mathrm{mL} \pm 0,004$ e $0,11 \mathrm{U} / \mathrm{mL} \pm 0,004$, respectivamente para as concentrações de $5 \%, 10 \%$ e $15 \%$ de ácido tânico (agente indutor) no meio de fermentação sólida. Entretanto, as variações da concentração durante os testes não apresentaram uma diferença significativa para o teste de Tukey $(p>0,05)$. Em virtude disso, os próximos ensaios seguiram com a concentração padrão de $5 \%$ de ácido tânico, utilizando menos reagente para o desenvolvimento dos testes seguintes.

\subsection{Influência da temperatura e do pH da reação enzimática com o substrato}

Foram realizados ensaios que variaram a temperatura de $20-100^{\circ} \mathrm{C}$ e o $\mathrm{pH}$ de $3,5-$ 9,5 na reação enzimática com o substrato (Figuras 7 e 8 ). 
Figura 7 - Efeito da temperatura da reação enzimática com o substrato.

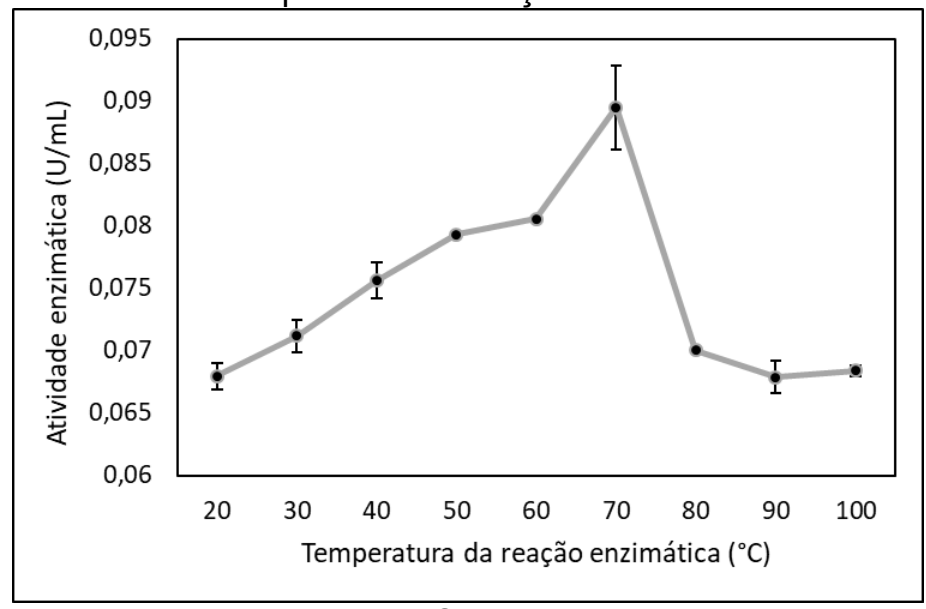

Fonte: Os autores.

Foi possível constatar que a atividade máxima foi determinada em $70^{\circ} \mathrm{C}$, com uma faixa ideal de atividade entre $50-70^{\circ} \mathrm{C}$, com valores de $0,079 \mathrm{U} / \mathrm{mL} \pm 0,0001,0,08 \mathrm{U} / \mathrm{mL}$ $\pm 0,0001$ e $0,09 \mathrm{U} / \mathrm{mL} \pm 0,003$, respectivamente, de forma que, com o aumento gradual da temperatura nos intervalos de 20 a $70^{\circ} \mathrm{C}$ houve um aumento correspondente de atividade enzimática, que passou de $0,068 \mathrm{U} / \mathrm{mL}\left(20^{\circ} \mathrm{C}\right)$ para $0,09 \mathrm{U} / \mathrm{mL}\left(70^{\circ} \mathrm{C}\right)$. Em contrapartida, a partir dos $80^{\circ} \mathrm{C}$, a atividade de enzima diminuiu significativamente. Estes resultados são semelhantes aos obtidos por Battestin (2007), que obteve atividade máxima em $60^{\circ} \mathrm{C}$, com uma faixa ideal de produção entre $40-60^{\circ} \mathrm{C}$, enquanto Cavalcanti e Guimarães (2018) encontraram temperatura ótima na faixa de $40-45^{\circ} \mathrm{C}$ para a atividade de tanase.

Figura 8 - Efeito do pH da reação enzimática com o substrato.

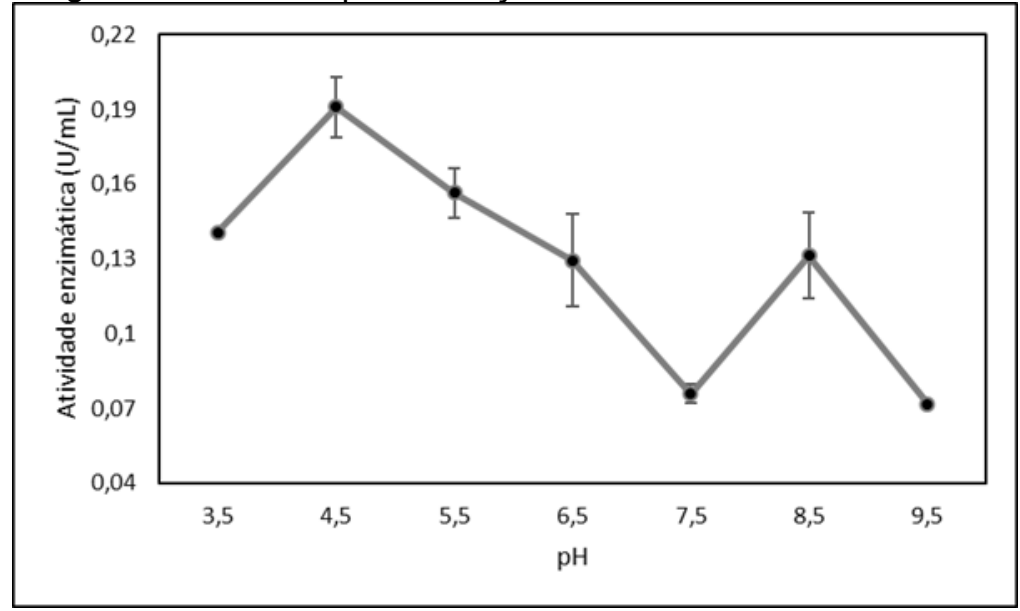

Fonte: Os autores.

Foi possível constatar que a atividade máxima foi determinada com $\mathrm{pH}=4,5$, apresentando atividade enzimática de $0,19 \mathrm{U} / \mathrm{mL} \pm 0,011$, com uma boa faixa de atividade entre 4,5 e 5,5, de forma que, com o aumento gradual do $\mathrm{pH}$ houve um decréscimo correspondente de atividade enzimática, que passou de $0,19 \mathrm{U} / \mathrm{mL}(\mathrm{pH}=4,5)$ para $0,07 \mathrm{U} / \mathrm{mL}(\mathrm{pH}=7,5)$. Estes valores são semelhantes aos encontrados por Battestin (2007), que demonstrou pH ótimo entre 4,0-5,5 para a enzima produzida por Aspergillus niger. Lal et al. (2012), por sua vez, obteve atividade máxima em pH-5,0, com tanases 
também produzidas por Aspergillus niger, enquanto Valera (2014) obteve bons resultados entre 5,0-5,5 com tanases produzidas por Aspergillus carbonarius. Em contrapartida, a reação realizada no $\mathrm{pH}=8,5$ apresentou um pequeno aumento de atividade $(0,13 \mathrm{U} / \mathrm{mL})$, sugerindo a existência de uma isoenzima, que corresponde a enzimas que catalisam a mesma reação, entretanto, não possuem necessariamente as mesmas propriedades físicas, devido a diferenças geneticamente determinadas na sequência de seus aminoácidos, assim, as isoenzimas podem apresentar diferentes números de aminoácidos. Um resultado semelhante foi obtido por Valera (2014), em que, com $\mathrm{pH}=8,0$, também relatou um pequeno pico de atividade enzimática, sugerindo que possivelmente também ocorreu a produção de uma isoenzima, assim como relatouse no presente trabalho.

\section{CONCLUSÕES}

A partir dos resultados obtidos com o desenvolvimento do trabalho, foi possível constatar que o resíduo da indústria cervejeira se configura em um ótimo resíduo agroindustrial empregado como substrato para a produção de biomoléculas através de fermentação em estado sólido a partir do fungo Aspergillus niger. Além disso, foram estabelecidos os melhores padrões para a otimização do processo biotecnológico, que se firmaram em testes com resíduo da produção industrial de cerveja, com o tampão acetato ( $\mathrm{pH} 5,0-0,2 \mathrm{M}$ ) como agente extrator, o preparo do meio de fermentação na proporção 1:1 com umidade de cerca de 52\%, 5 dias de incubação, com pH ótimo para a máxima atividade de tanase de $4,50,5 \%$ de agente indutor (ácido tânico) no meio fermentativo, e a reação enzimática realizada a $70^{\circ} \mathrm{C}$ no $\mathrm{pH}=4,50$.

Com base nisso, foi possível observar o aumento da atividade enzimática, passando de $0,04 \mathrm{U} / \mathrm{mL}$ para $0,19 \mathrm{U} / \mathrm{mL}$ ao final dos ensaios. Dessa forma, os próximos passos são direcionados ao início do processo de purificação da biomolécula produzida.

\section{REFERÊNCIAS}

AGUILAR, C. et al. A comparison of methods to determine Tannin Acyl Hydrolase Activity. Braz. Arch. Biol. Techonol., v. 42, n. 3, p. 355-361, 1999.

BANERJEE, D.; MONDAL, K. C.; PATI, B. R. Production and characterization of extracellular and intracelular tannase from newly isolated Aspergillus aculeatus DBF 9. J. Basic Microbiol., v.41, n.6, p.313-318, 2001.

BATTESTIN, V; MATSUDA, L. K.; MACEDO, G. A. Fonte e aplicações de taninos e tanases em alimentos. Alimentos e Nutrição, Araraquara, v. 25, n. 1, p. 63-72, 2004.

BATTESTIN, V. Produção, purificação e aplicação de tanase de Paecilomyces variotii. 2007. 99f. Tese (Doutorado em Ciências de alimentos) - Universidade Estadual de Campinas, Campinas, 2007.

BORGES, M. S.; SOUZA NETO, S. P. Meio ambiente $x$ Indústria de cerveja: um estudo 
de caso sobre práticas ambientais responsáveis. In: CONGRESSO NACIONAL DE EXCELÊNCIA EM GESTÃO, 5., 2009. Niterói. Anais..., Niterói: Universidade Federal Fluminense, 2009.

CABRAL FILHO, S. L. S. Avaliação do resíduo de cervejaria em dietas de ruminantes através de técnicas nucleares e correlativas. 1999. 82 f. Dissertação (Mestrado) - Universidade de São Paulo, Piracicaba, 1999.

CAVALCANTI, R. M. F.; GUIMARÃES, L. H. S. Produção e Caracterização Parcial de Tanase Pelo Fungo Endofítico Aspergillus Niger Ang 18 em Fermentação em Estado Sólido. Revista Saúde \& Ciência Online, v. 7, n. 2, p.426-440, ago. 2018.

COELHO, M. A. Z. et al. Aproveitamento de resíduos agroindustriais: produção de enzimas a partir da casca de coco verde. B. CEPPA, Curitiba, v. 19, n. 1, p. 33-42, 2001.

EL-FOULY, M. Z. et al. Biosynthesis and Characterization of Aspergillus niger AUMC 4301 Tannase. Journal of American Science, v. 6, n. 12, p. 709-721, 2010.

FERREIRA, L. R. Estudo da especificidade da tanase de Paecilomyces variotii e sua aplicação na biotransformação dos polifenóis do suco de laranja. 2011. $156 f$. Dissertação (Mestrado) - Universidade Estadual de Campinas, Campinas, 2011.

INSTITUTO ADOLFO LUTZ. Métodos físico-químicos para análise de alimentos. 4. ed. São Paulo: Instituto Adolfo Lutz, 2008.

KIELING, D. D. Enzimas: Aspectos Gerais. Florianópolis: Universidade Federal de Santa Catarina, 2002.

KRONBAUER, E. A. W. et al. Produção de xilanase por Aspergillus casielus com diferentes fontes de carbono. B. CEPPA, Curitiba, v. 25, n. 2, p. 207-216, 2007.

LAGEMAAT, J. V.; PYLE. D. L. Slid-state fermentation and bioremediation: development of a continuous process for the production of fungal tannase. Chem. Eng. J., v. 84, p. 15-123, 2001.

LAL, D. et al. Production of Tannin Acyl Hydrolase (E.C. 3.1.1.20) from Aspergillus niger isolated from bark of Acacia nilotica. Journal of Microbiology and Biotechnology Research, v. 2, n. 4, p.566-572, 2012.

LEKHA, P. K.; LONSANE, B. K. Comparative titres, location and properties of Tannin Acyl Hydrolase produced by Aspergillus niger PKL 104 in solid-state, liquid surface and submerged fermentations. Process Biochem. v. 29, p. 497-503, 1994.

MARCO, M. et al. A Novel Tannase from the Xerophilic Fungus Aspergillus niger GH1. Journal of Microbiology and Biotechnology, set. 2009.

MATHIAS, T. R. S.; MELLO, P. P. M.; SERVULO, E. F. C. Caracterização de resíduos cervejeiros. COBEQ. In: CONGRESSO BRASILEIRO DE ENGENHARIA QUÍMICA, 20. 2014. São Paulo. Anais..., Sãp Paulo: Blucher, 2014. p. 3805-3812.

MONDAL, K.C. BANERJEE, D.; JANA, M.; PATI, B.R. Colorimetric Assay Method for determination of the Tannin Acyl Hidrolase activity. Analytical Biochemistry, n. 295, p. 168-171. 2001. 
PANDEY, A. et al. Production of organic acids by solid-state fermentation. In: PANDEY A.; SOCCOL C.R.; LARROCHE C. (eds) Current Developments in Solid-state Fermentation. New Delhi: Asiatech Publishers, 2001. p. 113-126.

PELIZER, L. H.; PONTIERI, M. H.; MORAES, I. O. Utilização de resíduos agroindustriais em processos biotecnológicos como perspectiva de redução do impacto ambiental. Journal Of Technology Management \& Innovation, v. 2, n. 1, 2007.

PERLINGEIRO, C. A. G. Engenharia de Processos: análise, simulação, otimização e síntese de processos químicos. São Paulo: Blucher, 2005.

RECH, K. P. M.; ZORZAN, V. Aproveitamento de resíduos da indústria cervejeira na elaboração de cupcake. 2017. 44 f. Trabalho de Conclusão de Curso (Graduação em Tecnologia de Alimentos) - Universidade Tecnológica Federal do Paraná, Francisco Beltrão, 2017.

ROCHA, C. P. Otimização da produção de enzimas por Aspergillus niger em fermentação em estado sólido. Dissertação (Mestrado em Engenharias) Universidade Federal de Uberlândia, Uberlândia, 2010.

SCHONS, P. F.; RIES, F. E.; MACEDO, G. A. Fermentation and enzyme treatment on sorghum. Brazilian Journal of Microbiology, v. 1, p. 89-97, 2012.

SILVA, E. P. et al. Seleção de fungos do gênero Aspergillus produtores de tanase para inclusão em ração animal. Medicina Veterinária e Zootecnia, v. 12, n. 2, p.1-7, fev. 2018.

SRIVASTAVA, A.; KAR, R. Characterization and Application of Tannase Produced by Aspergillus niger ITCC 6514.07 On Pomegranate Rind. Brazilian Journal of Microbiology, n. 40, p.782-789, out. 2009.

TEIXEIRA, M. C. V.; VAZ, L.; BATTESTIN, V. Uso da biotecnologia na produção de enzimas. In: CONGRESSO INTERNACIONAL DE CIÊNCIA, TECNOLOGIA E DESENVOLVIMENTO, 6., 2017, Taubaté. Anais..., Taubaté, 2017.

VALERA, L. S. Produção e Caracterização das Tanases do Fungo Filamentoso Aspergillus carbonarius. 2014. 89 f. Dissertação (Mestrado) - Universidade Estadual Paulista, Araraquara, 2014. 